\title{
Feasible analysis of pulsating heat pipe applied to proton exchange membrane fuel cell
}

\author{
Fumin Shang ${ }^{1,2}$, Kangzhe Yang ${ }^{1}$, Chaoyue Liu ${ }^{1}$, Qingjing Yang ${ }^{1}$, Jianhong Liu ${ }^{1}$ \\ 1. Changchun Institute of Technology School of Energy and Power Engineering Changchun, China \\ 2. Jilin Engineering Research Center for Building Energy Supply and Indoor Environmental Control
}

\begin{abstract}
Proton exchange membrane fuel cell (PEMFC) has the advantages of high energy efficiency, clean, pollution-free, fast start-up and noise-free, but its thermal management problems still restrict the development and practical application of PEMFC. This paper analyzes the important influence of heat management on the working performance of proton exchange membrane fuel cell, and summarizes the structure principle and effect evaluation of thermal management system using heat pipe under the premise of simply summarizing the shortcomings of the thermal management system using conventional cooling method. By expounding the working principle and characteristics of pulsating heat pipe, and from the perspective of PEMFC internal structure and technology, the feasibility of applying pulsating heat pipe to PEMFC thermal management system is analyzed, with a view to developing pulsating heat pipe-type PEMFC thermal management technology with compact structure and excellent performance.
\end{abstract}

\section{Introduction}

With the increasingly serious problems of environment and resource, the sustainable development of energy has received more and more attention, the future development of human energy requirements are efficient, clean and cheap. Fuel cell is one of the important directions of the development of new energy field because of its good performance and wide application field, which has aroused the general concern of domestic and foreign industry researchers. And it is listed as the 21 st century high-tech by the United States Time magazine.

\section{PEMFC Overview}

A fuel cell is a device that converts the chemical energy of a fuel directly into electrical energy through electrochemical reactions[1]. Proton exchange membrane fuel cell (PEMFC) is a kind of fuel cell, composed of catalyst, electrode, bipolar plate and proton exchange membrane, it not only has the advantages of high efficiency cleaning, non-polluting, noise-free, but also has high power density, low operating temperature, strong corrosion resistance, rapid start-up, high reliability, long life and so on[2]. At present, PEMFC has been widely used in the automotive industry, aerospace, energy generation, household power supply and so on. It is the most promising fuel cell.

\section{PEMFC Thermal Management Research Status}

PEMFC work process is often accompanied by a large number of waste heat generation, waste heat dissipation and temperature control must be carried out to ensure the normal operating temperature of the battery.

Therefore, PEMFC thermal management is particularly important. Common battery cooling techniques are air-cooled[3-5], liquid-cooled[6-8], phase change material cooling[9-11] and so on. The traditional cooling method is to transfer heat from the inside of the battery through the bipolar plate and the cooling material (e.g. water), and then use air cooling to dissipate heat from the water or reuse the heat using air conditioning, so that the water can cycle the cooling battery[12]. With technological progress, miniaturization and integration have become the development trend of PEMFC, the heat dissipation per unit area of the battery has increased greatly, the traditional heat dissipation method has gradually been unable to meet the needs, and the design and development of a more efficient thermal management system to meet the heat dissipation needs of PEMFC has become a hot research topic in academia and industry at home and abroad, with important application value.

\section{Application of Heat Pipes in Fuel Cells}

Heat pipe is an efficient thermal conduction device based on phase change heat transfer, composed of tube shell, 
suction core, work quality, etc, can quickly and efficiently transfer heat energy from one place to another.

Xie Wen and others[13] use a micro-channel flat heat pipe applied to the space PEMFC thermal management system, the test proved that the use of flat-panel heat pipe heat dissipation can meet the needs of PEMFC battery reactor thermal management system.

B. Suman and others[14] have established a fluid flow and heat transfer analysis model of polygonal microthermal tubes to analyze fluid flow, heat and mass transfer. The study found that this heat pipe model is suitable for fuel cell cooling.

M.V.Oro and others[15] proposes a flat heat pipe that cools the PEMFC. It is found that this kind of heat pipe can meet the requirements of PEMFC cooling.

Sun Shiliang and others designed the PEMFC thermal management system (shown in Figure 1) that inserts the traditional heat pipe into the PEMFC battery pack bipolar plate, and the heat inside the battery is transmitted to the air through the heat pipe wall, achieving the goal of reducing the fuel cell temperature.

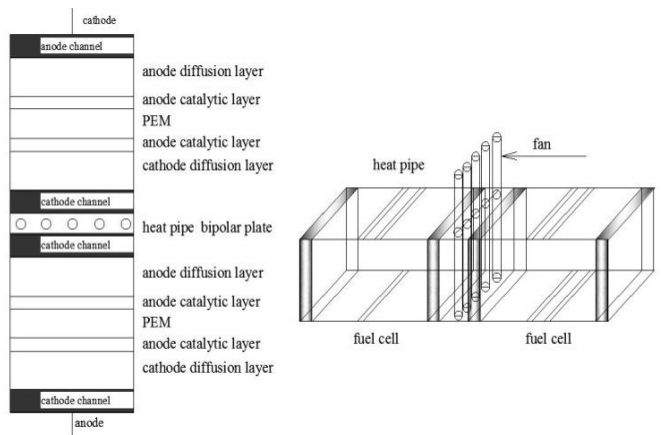

Fig.1. Heat-tube fuel cell thermal management system

Through the above analysis, it can be seen that the heat pipe has been widely used in the traditional fuel cell thermal management system. With the development of the battery industry, PEMFC integration and miniaturization of the rapid increase in power demand, resulting in high heat flow density of heat dissipation problems more and more serious, traditional heat pipe gradually difficult to meet the requirements. Pulsating heat pipe has become a better PEMFC radiator than conventional heat pipe because of its smaller size and higher heat transmission efficiency.

\section{Pulsating Heat Pipe and Application to PEMFC Feasibility}

Pulsating heat tube technology was first proposed by Akachi and others[16-18], according to the structure can be divided into circuit-type and non-loop-type pulsating heat pipe, as shown in Figure 2[19]. and according to it's appearance. It can be divided into two types of tube and plate.

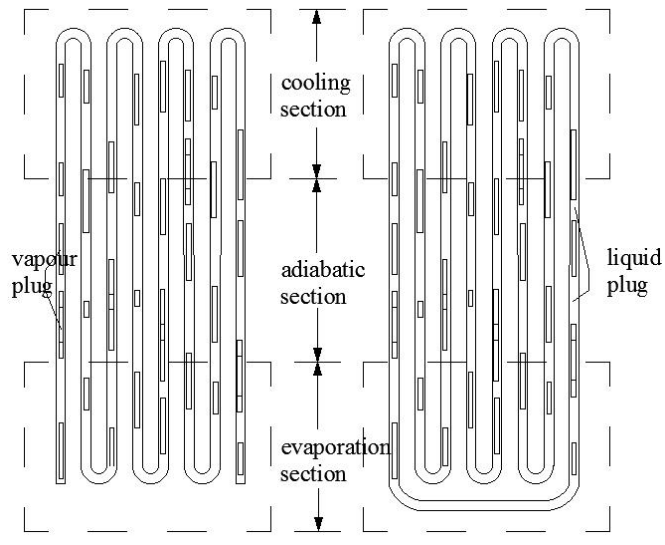

Fig.2. A brief diagram of the structure and working principle of the pulsating heat pipe

\subsection{How the pulsating heat pipe works and it's technical characteristics}

A pulsating heat pipe is a circular tube of a certain size or other type tube that bends to form multiple parallel paths with elbows, as shown in Figure 3.

Compared with traditional heat pipes, pulsating heat pipes have the following characteristics:

\subsubsection{The structure is simple and the size is small}

Due to the small internal diameter of the pulsating heat pipe (only $0.5 \mathrm{~mm}$ to $3 \mathrm{~mm}$ ), this determines that the size of the pulsating heat pipe is also relatively small, easy to achieve the use of miniaturized equipment and instruments[20]

\subsubsection{Strong ability to adapt to the environment}

Pulsating heat pipe can operate in environments such as gravity field inverted and gravity field changes.

\subsubsection{The heating position and heating method are flexible}

Due to the flexible arrangement of the pulsating heat pipe structure, the pulsating heat pipe in special operating conditions has the advantage that the traditional heat pipe can not be compared[21]. Gradually become the most promising high heat flow density, miniaturization and low-cost heat transmission elements[22].

\subsection{Pulsating heat pipes are used in PEMFC feasibility analysis}

\subsubsection{Pulsating heat pipe and PEMFC have structurally coordinated hardware conditions}

Since the actual proton exchange membrane fuel cell is mostly a proton exchange membrane fuel cell reactor, that is, composed of multiple single-cell series, as shown in Figure 3. 


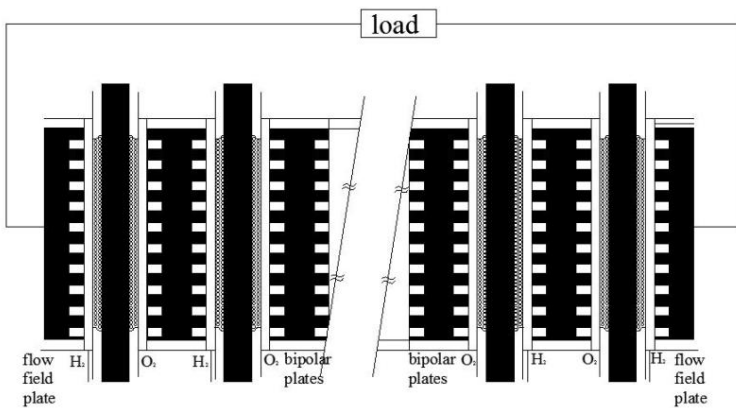

Fig.3. A diagram of the structure of the PEMFC battery stack

The bipolar plate has enough space and mechanical strength to ensure the installation and fixation of pulsating heat pipes.

\subsubsection{PEMFC's internal working environment can meet the technical requirements of pulsating heat pipe}

The pulsating heat pipe start-up temperature of conventional work quality is generally $45^{\circ} \mathrm{C}$, and between $60^{\circ} \mathrm{C}$ and $80^{\circ} \mathrm{C}$ can achieve the best operating conditions, while the normal operating temperature inside PEMFC is generally around $70^{\circ} \mathrm{C}$, and its material is mostly graphite and metal plate.

\subsubsection{Foreign heat-transmitting scholars have carried out relevant pilot studies}

Faghri and others[23-25] came up with the idea of using pulsating heat pipe in PEMFC bipolar plates, installing pulsating heat pipe in the currents on the back of PEMFC bipolar plates; Clement and others[26] have designed pulsating heat pipe for cooling the fuel cell reactor of proton exchange membranes.

\section{Conclusions and Prospects}

PEMFC will become one of the most promising research directions in the 21 st century because of its outstanding advantages of high efficiency, stability, convenience and environmental friendliness. With the large-scale development investment, the biggest obstacle to PEMFC application, cost, will be greatly reduced with the development of industrialization and commercialization. The large-scale application of PEMFC is no longer far away.

As a new type of thermal conduction device, pulsating heat pipe overcomes the shortcomings of traditional heat pipe which is susceptible to viscosity, capillary force constraints. pulsating heat pipe has the advantages of simple structure, fast heat response, high heat transmission efficiency, stable performance, low price, no power consumption and universality[27], and becomes a better PEMFC cooling device than traditional heat pipe, with high research value.

\section{Acknowledgment}

This work was supported by the science and technology development project of Jilin province (Grant numbers 20190303113SF), and industrial technology research and development project of Jilin province(2019C057-5).

\section{References}

1. Qiao Chengren, GuoHang, Ye Fang, Ma Heavyfang. PEMFC anode diffusion layer surface temperature and heat flow density joint measurement[J]. Journal of Engineering Thermophysics, 2020, 41 (07): 1792-1796.

2. Zhang Min. $75 \mathrm{~kW}$ proton exchange membrane fuel cell test bench thermal system design[J]. Agricultural Equipment and Vehicle Engineering, 2017, 55 (08): 15-18.

3. KITAGAWA Y, KATO K, FUKUI M. Analysis and experimentation for effective cooling of li-ion Batteries[J]. Procedia Technology, 2014, 18: 63-67.

4. WANG T, TSENG K J, ZHAO J Y, et al. Thermal investigation of lithium-ion battery module with different cell arrangement structures and forced air-cooling strategies[J]. Applied Energy, 2014, 134:229-238.

5. SUN H G, DIXON R. Development of cooling strategy for an air cooled lithium-ion battery pack[J]. Journal of Power Sources, 2014, 272(5):404-414.

6. TONG W, SOMASUNDARAM K, BIRGERSSON $E$, et al. Numerical investigation of water cooling for a lithium-ion bipolar battery pack[J]. International Journal of Thermal Sciences, 2015, 94:259-269.

7. LAN C J, XU J, QIAO Y, et al. Thermal management for high power lithium-ion battery by minichannel aluminum tubes[J]. Applied Thermal Engineering, 2016:284-292.

8. PANCHAL S, KHASOW R, DINCER I, et al. Thermal design and simulation of mini-channel cold plate for water cooled large sized prismatic lithium-ion battery $[\mathrm{J}]$. Applied Thermal Engineering, 2017, 122:80-90.

9. KIZILEL R, LATEEF A, SABBAH R, et al. Passive control of temperature excursion and uniformity in high-energy li-ion battery packs at high current and ambient temperature [J]. Journal of Power Sources, 2008, 183(1): 370-375.

10. DUAN X, NATERERB G F. Heat transfer in phase change materials for thermal management of electric vehicle battery modules[J]. International Journal of Heat and Mass Transfer, 2010, 53(23-24):5176-5182.

11. RAO Z H, WANG S F, ZHANG G Q. Simulation and experiment of thermal energy management with phase change material for ageing $\mathrm{LiFePO} 4$ power battery[J]. Energy Conversion \& Management, 2011, 52(12):3408-3414.

12. Sun Shiliang, Zheng Liqiu, Sun Shimei. Feasibility 
Study of Thermal Tube Technology for Fuel Cell Thermal Management Systems[J]. Journal of Jilin Institute of Construction Engineering, 2011, 28 (02): 40-42.

13. Xie Wen, Liu Jianfeng, Ma Yongjie, Li Peng, Li Leilei, Zhang Yuliang. Research on the thermal management technology of proton exchange membrane fuel cells for the space environment[J]. Electromechanical product development and innovation, 2017, 30 (05): 9-11.

14. SUMANB, KUMARP. An analytical model for fluid flow and heat transfer in a micro-heat pipe of polygonal shape [J]. Int J Heat Mass Transfer, 2005, 48(21-22): 4498-4509.

15. OROMV, BAZZOE. Flat heat pipes for potential application in fuel cell cooling[J]. Applied Thermal Engineering, 2015, 90:848-857.

16. Akachi H. Structure of a heat pipe: USA, 4921041[P]. 1990-05-01.

17. Akachi H. Structure of micro heat pipe: USA, 5219020[P]. 1993- 06-15

18. Akachi H. L type heat pipe: USA, 5490558[P]. 1996-02-13.

19. Cao Weijia. Pulsation heat pipe heat exchanger heat transfer performance and engineering application technology research[D]. Changchun Institute of Engineering, 2015.

20. Zhang Ziwen. Study on the flow and heat transmission characteristics of pulsation heat tubes and the rest of the heat recovery applications[D]. Southeast University, 2019.

21. Zhou Hua. Study on the flow and heat transmission performance of pulsation heat tubes in vibrational states[D]. Suzhou University of Science and Technology, 2019.

22. Qu Jian. Advances in the research and application of pulsation heat tube technology[J]. Chemical advances, 2013, (01): 33-41.

23. Fan Shilong. Experimental research and application of thermal transmission performance of pulsation heat pipe heat dissipation device[D]. Changchun Institute of Engineering, 2020.

24. Qu Jian. Advances in the research and application of pulsation heat tube technology[J]. Chemical advances, 2013, (01): 33-41.

25. F. Barbir, Fuel cell stack design principles with some design concepts of micromini fuel cells, in: NATO Science for Peace and Security Series (2008) $27 \mathrm{e} 46$.

26. Jason Clement, Xia Wang. Experimental investigation of pulsating heat pipe performance with regard to fuel cell cooling application[J]. Applied Thermal Engineering, 2013, 50(1).

27. Zhang Dongwei, Jiang Yihui, Zhou Junjie, Shen Chao, Xu Rongji, Yang Shaolun. Advances in the research of pulsation heat tube intensive heat transmission technology[J]. Science, Technology and Engineering, 2019, 19 (21): 1-7. 